DA SILVA, J. W. F.; PEREIRA, T. A.

Oportunidades da Química Teórica e Computacional para a Iniciação Científica

DOI: $10.31416 /$ rsdv.v8i2.43

\title{
Oportunidades da Química Teórica e Computacional para a Iniciação Científica
}

\author{
Theoretical and Computational Chemistry Opportunities for Undergraduate \\ Research
}

\author{
DA SILVA, José William Ferreira. Graduando em Licenciatura em Química \\ Instituto Federal do Sertão Pernamabucano - Campus Ouricuri. Estrada do Tamboril / SN - Ouricuri - \\ Pernambuco - Brasil. CEP: 56.2000-000 / Telefone: (87) 99819.3270 / E-mail: williamfsilva0@gmail.com
}

PEREIRA, Thamirys Alves. Graduanda em Licenciatura em Químimica

nstituto Federal do Sertão Pernamabucano - Campus Ouricuri. Estrada do Tamboril / SN - Ouricuri - Pernambuco - Brasil. CEP: 56.2000-000 / Telefone: (87) 99817.0342 / E-mail: thamirysalvespereira@gmail.com

\section{RESUMO}

Este trabalho apresenta uma introdução à Química Teórica e Computacional e às inúmeras possibilidades de linhas de pesquisa que a área pode oferecer para o ingresso à Iniciação Científica no Ensino Básico e Superior, por intermédio de um curso de Extensão Universitária ministrado na VIII Semana de Química e Meio Ambiente do Instituto Federal de Educação, Ciência e Tecnologia do Sertão Pernambucano - Campus Ouricuri. O minicurso teve duração de três dias, com carga horária total de 9 horas. Foram realizados estudos-piloto com ênfase nos aspectos práticos da Modelagem Molecular, em que os participantes tiveram a oportunidade de manipular softwares de Química Computacional, para o cálculo de propriedades geométricas e eletrônicas de moléculas orgânicas. As práticas possibilitaram uma ampla divulgação da área que, até então, ainda se encontra pouco difundida no meio acadêmico. 0 minicurso serviu como motivação para o registro de três projetos científicos voluntários na área de Química Computacional

Palavras-chave: Mecânica Quântica, Pesquisa Científica, Modelagem Molecular.

\begin{abstract}
This work presents an introduction to the theoretical and computational chemistry and the innumerable possibilities of research lines that the area can offer for the entrance to the undergraduate research, through a university extension course ministered in the VIII Semana de Química e Meio Ambiente do Instituto Federal de Educação, Ciência e Tecnologia do Sertão Pernambucano - Campus Ouricuri. The mini-course lasted for three days, with a total workload of 9 hours. We conducted pilot studies with emphasis on the practical aspects of molecular modeling, where participants had the opportunity to manipulate computational chemistry programs to calculate the geometric and electronic properties of organic molecules. The practices made possible a wide dissemination of the area that, until then, is little less widespread in the academic world. The mini-course served as motivation for the registration of three voluntary scientific projects in the area of computational chemistry.
\end{abstract}

keywords: Quantum Mechanics, Scientific Research, Molecular Modeling. 
DA SILVA, J. W. F.; PEREIRA, T. A.

Oportunidades da Química Teórica e Computacional para a Iniciação Científica

\section{Introdução}

A pesquisa científica, por meio do processo de descoberta, compreende a busca e a formulação de novos conhecimentos. Pesquisadores envolvidos em estudos com o propósito de contribuir para a ciência participam diretamente dos processos de coleta, de interpretação e de avaliação sistemática de dados de maneira articulada (CAPARLAR; DÖNMEZ, 2016). Este conjunto de sequências metódicas investigativas é introduzido no contexto escolar mediante programas de incentivo à Iniciação Científica (IC), tais como o Programa Institucional de Bolsas de Iniciação Científica (PIBIC), criado no Brasil em 1988 pelo Conselho Nacional de Desenvolvimento Científico e Tecnológico, CNPq (BRASIL, 2007).

Hunter, Laursen e Seymour (2006) destacaram o papel que a IC desempenha na formação de graduandos, mais especificamente no que se refere ao desenvolvimento pessoal, a construção de visão da ciência e a socialização profissional. Dentre outras vantagens, os alunos participantes de projetos de pesquisa sob supervisão de um mentor/orientador são capazes de desenvolver, sobretudo, autonomia para a tomada de decisões frente a problemas que exigem conhecimentos específicos.

As ciências químicas proporcionam inúmeros campos de estudo e, consequentemente, um leque de possibilidades para o desenvolvimento de projetos científicos. A Química Computacional, particularmente, emerge como um ramo da Química em constante evolução, oferecendo várias oportunidades para novos pesquisadores. Entretanto, em nível nacional, evidencia-se que essa área ainda é pouco divulgada no Ensino Superior e na Educação Básica. De acordo com Santos e Silva (2020), apenas 19 artigos que abordavam o tema "Simulações Computacionais no Ensino de Química” foram publicados durante o período 2008-2017. Concomitantemente, a pesquisa científica no Brasil caminha a passos curtos se comparada com países do hemisfério norte (Fig. 1), o que contribui para a não incorporação da ciência e da mentalidade científica de modo pleno na sociedade.

Assim, na forma de um curso de Extensão Universitária ministrado durante a VIII Semana de Química e Meio Ambiente (SQMA) do (IF Sertão Pernambucano) Instituto Federal de Educação, Ciência e Tecnologia do Sertão Pernambucano - Campus Ouricuri, sendo realizada entre os dias 18 e 21 de Junho de 2018, com o tema: “Química, Sociedade Sertaneja e Qualidade de Vida”, foi proposta uma maneira de introduzir as oportunidades da IC no desenvolvimento de trabalhos com o enfoque na Química Teórica e Computacional. O objetivo do curso foi de divulgar as várias linhas de atuação do pesquisador da área e, consequentemente, debater a importância da pesquisa científica para a evolução social, econômica e tecnológica do país, bem como incentivar a IC dentro do Campus.

O minicurso teve uma carga horária de 9 horas e ocorreu durante os três dias do evento, em que participaram 21 alunos dos cursos de Licenciatura Plena em Química, Ensino Médio Integrado ao Técnico em Informática, Técnico em Informática - Subsequente e Técnico em Edificações Subsequente. 
DA SILVA, J. W. F.; PEREIRA, T. A.

Oportunidades da Química Teórica e Computacional para a Iniciação Científica

Figura 1 - Mapa-múndi representado de acordo com a quantidade de trabalhos científicos produzidos. É possível observar que, no hemisfério norte, a pesquisa científica é mais difundida, enquanto que em países do hemisfério sul como no Brasil, esse tipo de produção é menos expressivo.

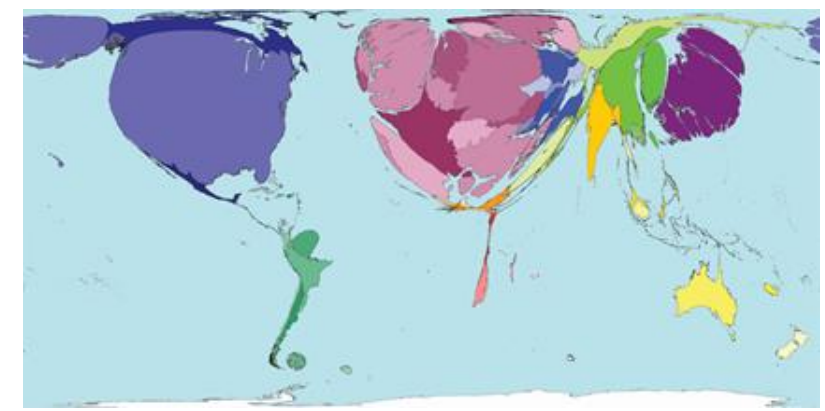

Fonte: (Hypescience).

\section{Metodologia}

Segundo Yin (2009), um estudo de caso é uma metodologia que envolve uma pesquisa e, normalmente, se utiliza de dados qualitativos - amostragem em uma determinada comunidade obtida através da experiência de quem observa - e tem por finalidade expor, de forma minimalista, os acontecimentos reais do contexto da averiguação. É comumente caracterizado por ser detalhado e, às vezes, exaustivo, sobretudo com experiências únicas vivenciadas por quem o faz. Nesta pesquisa foi feita uma abordagem qualitativa-descritiva da temática, baseando-se na proposta de Ogliari (2007) que afirma que investigar e analisar informações que se estuda, através de um conjunto de ações e objetivos, e é uma comunicação entre os dados coletados e analisados como

uma teoria de base.

O desenvolvimento deste trabalho teve como escopo a pesquisa qualitativa, fundamentada em suas cinco características básicas, de acordo com Ludke e André (1984):

1. O ambiente natural é a fonte direta de dados e o pesquisador é o principal instrumento;

2. os dados coletados são predominantemente descritivos;

3. a preocupação com o processo é muito maior do que com o produto;

4. o significado que as pessoas dão às coisas são os focos de atenção especial pelo pesquisador;

5. a análise de dados tende a seguir um processo indutivo.

\subsection{Campo de estudo}

Uma turma de 21 alunos da Rede Pública Federal de Ensino participou de um curso de Extensão Universitária, sendo este intitulado de "Oportunidades da Química Teórica e Computacional para a Iniciação Científica", e foi ministrado durante a VIII Semana de Química e 
DA SILVA, J. W. F.; PEREIRA, T. A.

Oportunidades da Química Teórica e Computacional para a Iniciação Científica

Meio Ambiente. Os temas abordados no encontro seguiram os moldes do projeto apresentado à comissão organizadora do evento. A carga horária total do minicurso foi de 9 horas e teve duração de 3 dias, ocorrendo no Laboratório de Informática do IF Sertão Pernambucano - Campus Ouricuri.

\subsection{Organização da estrutura do minicurso}

Para que os aspectos qualitativos fossem analisados durante a vigência do minicurso, cada dia foi dedicado à discussão de tópicos que contemplassem os objetivos inicialmente propostos. No primeiro dia, foram discutidos os temas: (I) Iniciação Científica; (II) Conceitos Essenciais da Química Teórica e Computacional; e (III) A Química Teórica e Computacional no Contexto da Iniciação Científica. No segundo dia, os tópicos abordados focaram em: (I) Modelagem Molecular de Proteínas; (II) Dinâmica Molecular; e (III) Campos de Pesquisa em Modelagem Molecular. 0 terceiro dia foi dedicado aos tópicos: (I) Estudos de Docking Molecular; (II) Perspectivas da Iniciação Científica no IF Sertão Pernambucano - Campus Ouricuri; e (III) Percepções sobre o minicurso.

Com o intuito de que os alunos pudessem ter uma melhor imersão no minicurso, estudospiloto foram devidamente elaborados considerando os aspectos práticos da realização de cálculos quânticos e de Modelagem Molecular. Preocupação especial foi atribuída aos conhecimentos prévios do público-alvo, a adaptação da linguagem científica e a limitação dos recursos computacionais existentes.

\subsection{Arquitetura do artigo}

Durante a discussão dos resultados, optamos por incluir uma pequena fundamentação teórica e algumas reflexões em cada subtópico, seguidas da descrição metodológica detalhada de todos os estudos-piloto aplicados. Isso acompanhando a lógica da organização estrutural do minicurso, desde sua aprovação pela comissão organizadora do evento até a sua consolidação e sua realização.

\section{Resultados e discussão}

\subsection{Semana de Química e Meio Ambiente: Registro e Divulgação do Minicurso}

A SQMA do IF Sertão Pernambucano - Campus Ouricuri é um evento que ocorre anualmente, mais especificamente no mês de junho. A oitava edição do evento, cujo tema foi "Química, Sociedade Sertaneja e Qualidade de Vida", contou com palestras, com oficinas, com minicursos, com feira de profissões, com feira de saúde, com apresentação cultural, com apresentação de trabalhos e com sorteio de brindes. O evento é organizado pela coordenação do curso de Licenciatura em Química em colaboração com monitores, e se consagra no calendário da instituição por oferecer uma excelente programação para os alunos de Graduação, de Ensino Médio, e de PROEJA, para os técnicos, para os professores e para a comunidade em geral. Os participantes 
DA SILVA, J. W. F.; PEREIRA, T. A.

Oportunidades da Química Teórica e Computacional para a Iniciação Científica

puderam realizar suas inscrições pelo site do IFEventos (https://ifeventos.ifsertaope.edu.br/public/event/26).

A proposta do minicurso: “Oportunidades da Química Teórica e Computacional para a Iniciação Científica" foi avaliada e aprovada de acordo com os critérios estabelecidos pela comissão organizadora do evento. O minicurso foi incluído na programação e registrado no servidor do IFEventos, em que foram disponibilizadas 30 vagas, ocorreu no período noturno com duração de 3 horas por dia, totalizando uma carga horária de 9 horas, e contou com certificado de participação incluso. Uma arte própria foi elaborada para a divulgação do minicurso nas principais redes sociais.

Um total de 21 alunos regularmente matriculados na instituição se inscreveram, de forma que a divisão em função do curso é mostrada na tabela 1. 0 maior número de interessados pelo tema se concentrou nos cursos de Ensino Médio Integrado ao Técnico em Informática e Licenciatura Plena em Química.

Tabela 1 - Alunos inscritos no minicurso.

Curso

Alunos por curso

\begin{tabular}{lc}
\hline Ensino Médio Integrado ao Técnico em Informática & 8 \\
Licenciatura Plena em Química & 7 \\
Técnico em Informática - Subsequente & 4 \\
Técnico em Edificações - Subsequente & 1 \\
Professor & 1 \\
\hline
\end{tabular}

Fonte: Dos autores.

\subsection{Primeiro dia}

Inicialmente, todos os inscritos se apresentaram como professor e alunos regularmente matriculados na instituição, enfatizando seus respectivos cursos. Para que houvesse uma melhor colaboração/interação entre os ministrantes e os alunos, todos os arquivos auxiliares, incluindo slides, material de apoio e atividades extras, foram carregados previamente em um serviço de armazenamento em nuvem, por meio do qual os discentes poderiam acessar a pasta antes, durante e após a vigência do minicurso. Em seguida, foram apresentados os objetivos e os tópicos que seriam abordados neste dia como forma de ambientação.

\subsubsection{Iniciação científica}

Para a discussão deste tópico, foi distribuída para cada participante uma ferramenta metacognitiva conhecida como quadro SQA, originalmente criada pela professora Ogle (1986). Basicamente, esta ferramenta funciona como um guia de aprendizagem para conteúdos específicos, focando em três questões fundamentais: $\mathrm{S}$ - Saber ( $\mathrm{O}$ que eu sei sobre isso atualmente?); Q - Querer saber ( $\mathrm{O}$ que eu quero aprender?); A - Aprender ( $\mathrm{O}$ que eu aprendi?). Foi estipulado um tempo de cinco minutos para que todos pudessem preencher as colunas " $\mathrm{S}$ " $\mathrm{e}$ "Q" do quadro. Em seguida, os 
DA SILVA, J. W. F.; PEREIRA, T. A.

Oportunidades da Química Teórica e Computacional para a Iniciação Científica

participantes, um a um, foram convidados a compartilhar o que haviam escrito para o restante do grupo. Cerca de $98 \%$ do público relatou na coluna S não conhecer nada sobre o assunto. Logo, as perguntas predominantes na coluna $Q$ foram: “O que é a Iniciação Científica?" e "Para que serve a Iniciação Científica"? Curiosamente, apenas uma aluna do curso de Licenciatura Plena em Química conseguiu preencher a coluna S, pois já havia participado de um projeto de IC (Quadro 1).

De acordo com a porcentagem de discentes que não preencheram a coluna $\mathrm{S}$ com conhecimentos prévios, nota-se que a Iniciação Científica ainda é pouca difundida. Isso é refletido na pequena quantidade de trabalhos publicados que visam a discutir as vantagens e desvantagens das pesquisas científicas no âmbito da educação formal (MASSI; QUEIROZ, 2010). Essa problemática pode estar relacionada ao aprender a pesquisar (LATOUR; WOOLGAR, 1997). Essencialmente, essa prática pode ser adquirida quando nos submetemos diretamente a atividades científicas. Nesse contexto, deve-se entender que o processo é permeado por tentativas, por erros e por acertos, sendo que a investigação é um produto do avanço do conhecimento envolvido.

Quadro 1 - Quadro SQA preenchido por uma aluna do curso de licenciatura em Química

\begin{tabular}{|c|c|c|}
\hline SABER (S) & QUERER (Q) & APRENDER (A) \\
O que eu sei? & O que eu quero saber? & \\
\hline $\begin{array}{c}\text { A Iniciação Científica (IC) é uma uprendi? } \\
\text { oportunidade oferecida para os } \\
\text { estudantes no âmbito da } \\
\text { pesquisa científica em } \\
\text { determinada área do } \\
\text { Quais são as linhas de pesquisa da } \\
\text { Química Teórica e Computacional? } \\
\text { conhecimento, com o intuito de } \\
\text { preparar o pesquisador para a } \\
\text { vida acadêmica, que por sua } \\
\text { vez contribui diretamente para } \\
\text { o desenvolvimento pessoal e } \\
\text { profissional do aluno envolvido } \\
\text { nesse processo. }\end{array}$ & \\
\hline
\end{tabular}

*Os discentes foram orientados a preencher a coluna " $A$ " como forma de autoavaliação ao término do minicurso. Como não houve um reencontro posterior, os folhetos não foram recolhidos.

Os programas de incentivo à Iniciação Científica (PIBIC) se apresentam como uma solução para essa problemática. Basicamente, o contato inicial dos alunos com pesquisas científicas ocorre no Ensino Médio e na Graduação por intermédio de projetos propostos por editais, que contemplam os campos das ciências exatas, humanas e linguagens.

O objetivo geral do PIBIC é centrado na formação de pesquisadores qualificados, baseandose na experiência da Iniciação Científica e na motivação, para que o graduando se oriente rumo à Pós-Graduação (NOGUEIRA; CANAAN, 2009). Os objetivos específicos do programa são:

- Despertar a vocação científica e incentivar novos talentos entre estudantes de graduação;

- Contribuir para reduzir o tempo médio de titulação de mestres e doutores;

- Contribuir para a formação científica de recursos humanos que se dedicarão a qualquer 
DA SILVA, J. W. F.; PEREIRA, T. A.

Oportunidades da Química Teórica e Computacional para a Iniciação Científica

atividade profissional;

- Estimular uma maior articulação entre a graduação e pós-graduação;

- Contribuir para a formação de recursos humanos para a pesquisa;

- Contribuir para reduzir o tempo médio de permanência dos alunos na pós-graduação;

- Estimular pesquisadores produtivos a envolverem alunos de graduação nas atividades científica, tecnológica e artístico-cultural;

- Proporcionar ao bolsista, orientado por pesquisador qualificado, a aprendizagem de técnicas e métodos de pesquisa, bem como estimular o desenvolvimento do pensar cientificamente e da criatividade, decorrentes das condições criadas pelo confronto direto com os problemas de pesquisa; e

- Ampliar o acesso e a integração do estudante à cultura científica (BRASIL, 2007).

\subsubsection{Introdução à Química Teórica e Computacional: conceitos essenciais}

No contexto científico, o foco da Química Computacional é centrado na solução de problemas químicos por intermédio das leis da mecânica quântica incorporados a programas de computador (IUPAC, 1998). Essencialmente, é incumbência da Química Computacional calcular estruturas e propriedades intrínsecas de moléculas. Para tal, utilizam-se métodos que abrangem situações estáticas e dinâmicas, principalmente no que diz respeito à solução do "problema de muitos corpos", isto é, problemas físicos que estão relacionados às propriedades de sistemas microscópicos constituídos de muitas partículas que interagem. Basicamente, a Química Computacional é um dos ramos da Química Teórica (Fig. 2).

A ideia fundamental da Química Quântica é o comportamento ondulatório-corpuscular da luz e das partículas que constituem a matéria. Este fenômeno é observado quando o momento linear das partículas é igual à constante de Planck ( $h=6,6260693 \times 10^{-34} \mathrm{~J} \cdot \mathrm{s}$ ). Por essa razão, a Mecânica Quântica foi desenvolvida de uma maneira não trivial, tornando-se uma teoria abstrata. Foi formulada desde os primeiros trabalhos de Max Planck em 1900 sobre a radiação do corpo negro (PLANCK, 1900) até sua consolidação no final dos anos de 1920 com a criação de suas equações fundamentais: a equação de Schrödinger (SCHRÖDINGER, 1926) e o Princípio da Incerteza de Heisenberg (HEISENBERG, 1927). 
DA SILVA, J. W. F.; PEREIRA, T. A.

Oportunidades da Química Teórica e Computacional para a Iniciação Científica

Figura 2 - Ramos da Química Teórica.

\section{RAMOS DA QUÍMICA TEÓRICA}

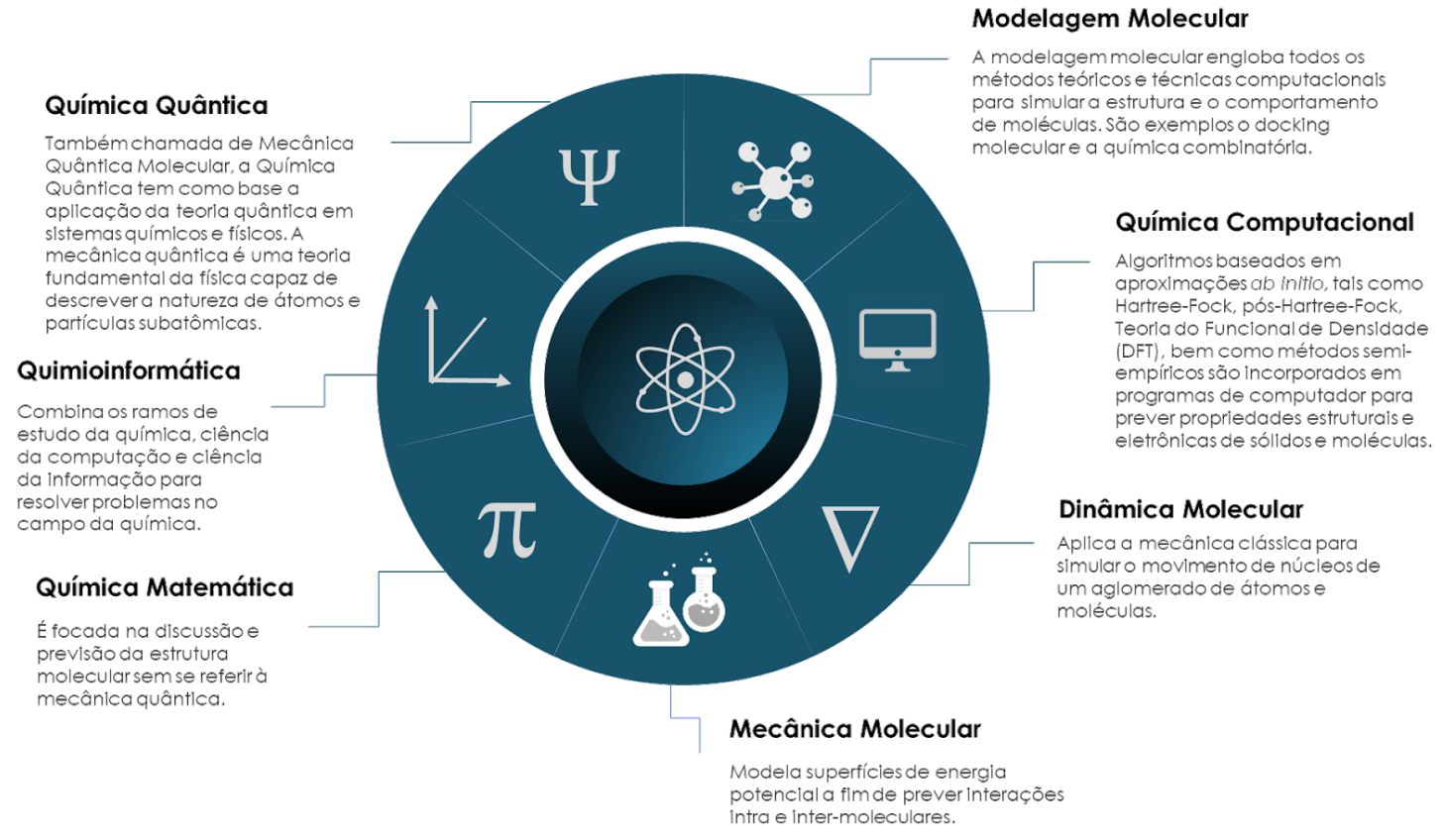

Fonte: Dos autores.

A maior parte dos cálculos e das simulações da Química Computacional se apoiam na Equação de Schrödinger (Eq. 1) por descrever completamente o estado quântico do sistema estudado através de uma função de onda. Em Mecânica Quântica, a função de onda eletrônica $(\Psi)$ é descrita como uma entidade matemática que carrega as informações a respeito de um sistema de uma ou de mais partículas, sendo crucial para a determinação de suas propriedades. Admitindo a aproximação de Born-Oppenheimer e desprezando quaisquer efeitos relativísticos, a Equação de Schrödinger pode ser resolvida:

$H \Psi=E \Psi$

em que $\mathrm{H}$ é o Hamiltoniano molecular (Eq. 2), que opera sobre $\Psi$ e devolve a energia total do sistema $(E)$

$H=-\sum_{i=1}^{N} \frac{\hbar^{2}}{2 m} \nabla_{i}^{2}-\sum_{i=1}^{N} \sum_{A=1}^{M} \frac{Z_{A} e^{2}}{4 \pi \epsilon_{o} r_{i A}}+\sum_{i=1}^{N} \sum_{j>1}^{N} \frac{e^{2}}{4 \pi \epsilon_{o} r_{i j}}$

em que 
DA SILVA, J. W. F.; PEREIRA, T. A.

Oportunidades da Química Teórica e Computacional para a Iniciação Científica

$-\sum_{i=1}^{N} \frac{\hbar^{2}}{2 m} \nabla_{i}^{2}$

descreve a energia cinética dos elétrons e $\nabla^{2}$ (nabla) é o operador laplaciano. Nesta expressão, $m$ é a massa do elétron e $\hbar$ é a constante reduzida de Planck.

$-\sum_{i=1}^{N} \sum_{A=1}^{M} \frac{Z_{A} e^{2}}{4 \pi \epsilon_{o} r_{i A}}$

A equação 2.2 descreve a atração eletrostática entre um elétron qualquer e o núcleo (reduz a energia do sistema), em que $Z_{A}$ é o núcleo atômico do núcleo $A$ e $r_{i A}$ é a distância entre o elétron $i$ e o núcleo $A$. $N$ e $M$ indicam, respectivamente, os números de elétrons e de núcleos do sistema.

$+\sum_{i=1}^{N} \sum_{j>1}^{N} \frac{e^{2}}{4 \pi \epsilon_{o} r_{i j}}$

A equação 2.3 representa a repulsão elétron-elétron (aumenta a energia do sistema). $r_{i j}$ é a distância entre os elétrons $i$ e $j$.

Para o átomo de hidrogênio, a Equação de Schrödinger possui solução analítica. Todavia, para átomos polieletrônicos ou para moléculas, a solução exata, em geral, não é factível devido aos parâmetros considerados no Hamiltoniano molecular, como a energia de repulsão elétron-elétron, tornando necessária a utilização de modelos descritivos aproximados, tais como o método HartreeFock, HF (HARTREE, 1928), os métodos semiempíricos, SE (ZERNER, 1991) e a Teoria do Funcional de Densidade (do inglês, Density-Functional Theory, DFT) (RUNGE; GROSS, 1984).

Vários softwares de Química Computacional possuem métodos HF, SE e DFT implementados. Dentre eles, destacam-se: MOPAC (STEWART, 2016), Hyperchem (FROIMOWITZ, 1993), Gaussian (FRISCH et al., 2016), Q-Chem (SHAO et al., 2015), Spartan (HEHRE, 2000) e GAMESS (SCHMIDT et al., 1993). Cada um deles possui sua interface gráfica associada, o que permite a visualização dos resultados, por exemplo, de energias relativas e absolutas, de momentos de dipolo e multipolares superiores, de distribuições eletrônicas de densidade de carga e de frequências vibracionais.

\subsubsection{Estudo piloto 1 - obtendo as cargas parciais do Hidroxibenzeno pelo Semiempírico RM1}

Nesta etapa, os alunos tiveram a oportunidade de manipular alguns softwares para a visualização de propriedades estruturais e eletrônicas discutidas previamente. Para a realização dos cálculos foi selecionada a molécula de Hidroxibenzeno $\left(\mathrm{C}_{6} \mathrm{H}_{5} \mathrm{OH}\right)$, o fenol mais simples, que consiste em uma hidroxila $\left(\mathrm{OH}^{-}\right)$ligada ao anel benzênico. Esse composto foi selecionado porque é usado como material de partida para a fabricação de plásticos, de explosivos e de drogas como a aspirina, caracterizando inúmeras aplicações industriais.

Após as orientações necessárias sobre os comandos básicos dos softwares que seriam 
DA SILVA, J. W. F.; PEREIRA, T. A.

Oportunidades da Química Teórica e Computacional para a Iniciação Científica

utilizados, as etapas de obtenção de geometria e de propriedades da molécula de Hidroxibenzeno foram as seguintes:

1. A estrutura bidimensional (2D) do Hidroxibenzeno foi desenhada manualmente e otimizada no software ChemSketch (ACD/LABS, 2015) após consulta prévia de sua conformação no banco de dados de moléculas orgânicas, PubChem (KIM et al., 2015). Os dados das coordenadas atômicas $x, y$ e $z$ da molécula foram exportadas no formato de entrada (input) MDL Molfile (extensão .mol);

2. no software de edição e de visualização, Avogadro (HANWELL et al., 2012), o arquivo de entrada foi convertido em sua estrutura tridimensional (3D) e preparado em MOP (Mopac Input File) de acordo com o método semiempírico Recife Model 1, RM1 (ROCHA et al., 2006), combinado com o algoritmo de otimização padrão Eigenvector Following, EF (BAKER, 1986);

3. a geometria final e a energia mais favorável associada foram calculadas até os ciclos máximos necessários para a convergência (ponto de parada) no software MOPAC/2016;

4. as propriedades Entalpia Padrão de Formação $\left(\Delta H^{\circ} f\right)$, Energia de lonização (El), Momento de Dipolo Elétrico, Energia do HOMO (highest occupied molecular orbital) e do LUMO (lowest unoccupied molecular orbital), Área de Superfície Molecular e Volume Molecular foram analisadas. Dados experimentais disponíveis no NIST (LINSTROM; MALLARD, 2001) foram comparados com os dados teóricos calculados no MOPAC/2016;

5. por fim, um mapa de potencial eletrostático para a molécula de Hidroxibenzeno foi gerado no software Jmol (http://www.jmol.org/).

Os resultados mostraram que a conformação ativa para o Hidroxibenzeno era de 4492,54844 Elétron-volts (eV). Esse valor representa a energia potencial mínima calculada após a convergência da geometria mais estável da molécula (parâmetro conhecido como energia de campo autoconsistente, SCF) em um tempo computacional de 0,609 segundos (s). A configuração mais energeticamente favorável para o composto se correlacionou com um $\Delta H^{\circ} f$ igual a $-96,35$ Quilojoules por mol ( $\mathrm{kJ} / \mathrm{mol}$ ) em uma temperatura de 298,15 Kelvin (K), aproximando-se do valor experimental reportado no NIST $(-96,35 \mathrm{~kJ} / \mathrm{mol})$. A energia de ionização e o momento de dipolo foram 8,932 e 1,224 eV, respectivamente, equiparando-se também aos valores do NIST (8,508 e $1,224 \mathrm{eV}$ ). A figura 3B mostra um resumo dos resultados obtidos após a convergência do cálculo.

O mapa de potencial eletrostático representado na figura 3A ilustra a distribuição de carga na molécula em sua forma 3D, em que as áreas de baixo potencial (vermelho) indicam uma abundância de elétrons, enquanto que as áreas de alto potencial (azul) correspondem a uma relativa ausência de elétrons. O conhecimento das distribuições de carga pode ser usado para visualizar a forma e o tamanho das moléculas, bem como determinar interações intra e intermoleculares.

Nesse caso, o átomo de oxigênio (0) da hidroxila é uma região de alta densidade eletrônica em função de sua eletronegatividade e dos pares de elétrons isolados. Isso quer dizer que o átomo 
DA SILVA, J. W. F.; PEREIRA, T. A.

Oportunidades da Química Teórica e Computacional para a Iniciação Científica

de 0 pode atuar como uma base de Lewis (nucleófilo) A baixa densidade eletrônica no átomo de hidrogênio $(H)$ da hidroxila e a conjugação do anel tornam os fenóis mais ácidos (pKa 10) do que os álcoois (pKa 16).

Figura 3 - A) Estrutura tridimensional e mapa de potencial eletrostático do Hidroxibenzeno obtido por RM1; as distâncias inter-atômicas estão descritas em nanômetros (nm); as cores cinza, branco e vermelho das esferas representam os átomos de carbono (C), de hidrogênio $(\mathrm{H})$ e de oxigênio $(\mathrm{O})$, respectivamente. (B) Dados de saída do MOPAC/2016 expondo as propriedades eletrônicas e geométricas da molécula.

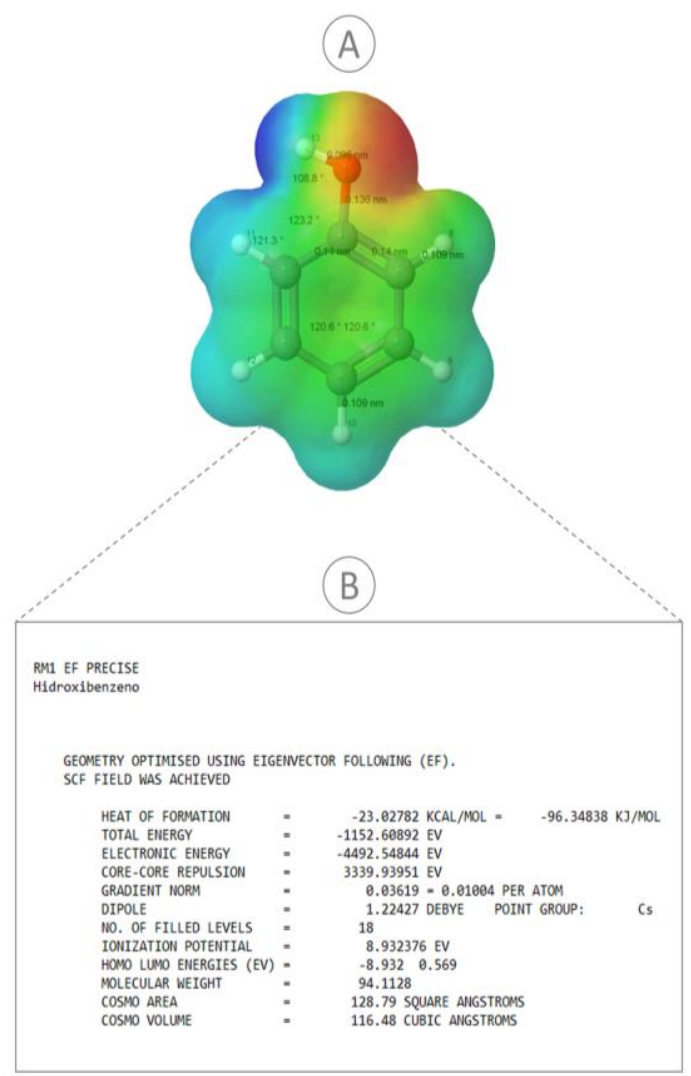

Fonte: Dos autores.

\subsubsection{A Química Teórica e Computacional no contexto da Iniciação Científica}

A introdução de conceitos da Química Teórica e Computacional na Educação Básica ou mesmo a nível de Graduação pode ser uma tarefa estarrecedora. Geralmente, os alunos não vivenciam assuntos que contemplem os conteúdos de equações diferenciais ou até mesmo álgebra linear em sua matriz curricular. É de práxis, portanto, que os fundamentos da Mecânica Quântica e, consequentemente, da Química Computacional apareçam apenas, em alguns casos, no último ano da Graduação ou em cursos de Pós-Graduação stricto sensu. Ao mesmo tempo, a Modelagem Computacional é geralmente ignorada no ensino de ciências, apesar de ser um elemento essencial da construção científica e da construção cognitiva (MOREIRA, 2014). Por essa razão, os estudantes 
DA SILVA, J. W. F.; PEREIRA, T. A

Oportunidades da Química Teórica e Computacional para a Iniciação Científica

acabam desconhecendo a importância, a abrangência e as limitações dessa área no campo da pesquisa. Segundo Pearson (2007), “[...] isso é lamentável, pois o campo cresceu e se tornou uma ferramenta importante para os químicos de todas as disciplinas e pode fornecer uma experiência valiosa aos alunos de qualquer nível (tradução nossa)".

Uma das maiores dificuldades em Química Computacional é interpretar como o algoritmo implementado no software, baseado na Mecânica Quântica, entrega o resultado final. Alguns trabalhos têm se empenhado em contornar esta situação com a aplicação de estudos-piloto em sala de aula (FELLER; DALLINGERE; MCKINNEY, 2004; OCHTERSKI, 2014). Esse aspecto é importante porque pode funcionar como ponto de partida para o incentivo ao desenvolvimento de projetos de pesquisa originais

É reconhecido que a Química Teórica e Computacional oferece inúmeras oportunidades de estudos investigativos devido a quantidade de softwares disponíveis de códigos fechado e livre, como os citados na seção anterior. Por sua vez, a evolução tecnológica em conjuntura com a criação de algoritmos aprimorados, tais como o surgimento de métodos de escalonamento verdadeiramente linear do tipo MOZYME (STEWART, 1996) e LocalSCF (ANIKIN et al., 2004) para métodos semiempíricos têm viabilizado a execução de cálculos de função de onda, de energia total, de pKa, de localização de orbitais de fronteira etc. para moléculas com extensa amostragem conformacional (proteínas) em computadores de uso doméstico. Por exemplo, Anikin et al. (2004) conseguiram calcular a função de onda e a energia total de um sistema fundamental para o dobramento adequado de muitas proteínas, o GroEL-GroES-Chaperonina contendo 119 mil átomos em um computador doméstico com processador Pentium 4 de 2,4 GHz e Windows 2000 em aproximadamente 4,5 horas.

Pesquisas nesse ramo ainda podem ser facilitadas com os Centros Nacionais de Processamento de Alto Desempenho (CENAPAD). Os CENAPAD emergem como uma ótima possibilidade de acesso à infraestrutura computacional de ponta na ausência de máquinas pessoais, adaptando-se mais adequadamente à natureza da pesquisa. O CENAPAD-SP, a título de exemplo, é um dos nove Centros Nacionais de Processamento de Alto Desempenho que compõem o programa SINAPAD, criado em 1994 (CENAPAD-SP, 2018a). Os processadores disponíveis permitem que o pesquisador realize cálculos em pequenas e em grandes moléculas por meio de métodos mais robustos, como os baseados em primeiros princípios (ab initio). Desde sua fundação em 1994 até a presente data (15 de Dezembro de 2018), as publicações nacionais e internacionais geradas a partir de trabalhos que usaram recursos computacionais do CENAPAD-SP chegam a 3499, incluindo artigos e livros (CENAPAD-SP, 2018b). 0 acesso ao sistema ocorre sob requerimento de um projeto de pesquisa devidamente assinado pelo pesquisador e pelo orientador. Relatórios são cobrados pela equipe coordenadora a fim de fiscalizar o uso adequado dos softwares.

Atualmente, a única revista científica brasileira existente com foco e com escopo específico em áreas afins da Química Teórica e Computacional é a Computational \& Applied Mathematics (ISSN 0101-8205 versão impressa; ISSN 1807-0302 versão online). Considerando apenas as métricas de produção do CENAPAD-SP, aproximadamente 146 trabalhos originais brasileiros são publicados por ano. Esse número mostra como o campo de pesquisa tem acompanhado a evolução tecnológica, 
DA SILVA, J. W. F.; PEREIRA, T. A.

Oportunidades da Química Teórica e Computacional para a Iniciação Científica

ganhando cada vez mais espaço. É notório, portanto, que o maior número de produções científicas se concentra no exterior, já que lá constam inúmeras revistas conceituadas. Exemplo de algumas são:

- Journal of Chemical Theory and Computation;

- Journal of Chemical Information and Modelling;

- Journal of Computational Chemistry;

- Journal of Molecular Graphics and Modeling;

- Computational and Theoretical Chemistry;

- Journal of Molecular Modeling.

Um dos eventos mais importantes de divulgação científica em Química Teórica e Computacional que ocorre no Brasil a cada dois anos, é o Simpósio Brasileiro de Química Teórica (SBQT). Na sua última edição, em 2017, o SBQT completou 36 anos, destinando-se a reunir pesquisadores de diversas áreas, incluindo: Mecânica Quântica, Mecânica Estatística, Modelagem Molecular, Simulação Computacional de Sistemas Líquidos e Sólidos, Desenvolvimento de Algoritmos e outras, visando a contemplar as diferentes linhas de pesquisa existentes na comunidade de Química Teórica e Física Molecular no país. Ao todo, 328 resumos simples foram submetidos (SBQT, 2017).

\subsection{Segundo dia}

\subsubsection{Introdução à Modelagem Molecular}

A Modelagem Molecular utiliza todos os métodos, teóricos e computacionais, para representar sistemas moleculares por meio de modelos conceituais baseados na Mecânica Quântica ou na Mecânica Molecular (que engloba os fundamentos da Mecânica Pré-Relativística). É, possivelmente, um dos campos que mais vem ganhando destaque na Química Teórica, principalmente no que se refere às suas aplicações dentro da Bioinformática, Química Computacional, Ciências dos Materiais e desenvolvimento de fármacos.

Idealmente, a importância de se estudar os conceitos da Modelagem Molecular, está no fato de que, em nível experimental, os químicos sempre procuram estabelecer relações entre a descoberta de novos materiais com sua estrutura molecular, e a modelagem molecular nos permite analisar, interpretar e entender as leis que governam o comportamento químico de um sistema na sua forma mais intrínseca.

Considerando as inúmeras aplicações da Modelagem Molecular nos diversos campos de pesquisa, será abordado, na próxima seção, a “Modelagem de Proteínas por Homologia”, que serviu como estudo piloto para o momento prático do minicurso no segundo dia. Este método foi escolhido porque é amplamente utilizado como base para investigar a estrutura, a dinâmica, as propriedades de superfície e a termodinâmica de sistemas poliméricos biológicos. Vale destacar que, 
DA SILVA, J. W. F.; PEREIRA, T. A.

Oportunidades da Química Teórica e Computacional para a Iniciação Científica

indiretamente, já foi exemplificado um caso que envolve a Modelagem Molecular no estudo piloto 1, quando os discentes geraram o mapa de potencial eletrostático da molécula de hidroxibenzeno e desenharam sua estrutura 3D.

\subsubsection{Modelagem de Proteínas por Homologia}

A técnica conhecida como Modelagem de Proteínas por Homologia é bem reportada na literatura (SANCHEZ; SALI, 1997). É bastante empregada na Bioinformática Estrutural, uma área que é encarregada de compreender como macromoléculas (e.g. DNA, RNA, proteínas e outros compostos de baixo peso molecular) interagem, considerando as suas funções e estruturas 3D. Rotineiramente, o desenvolvimento de novos fármacos é uma das grandes aplicações da Modelagem de Proteínas por Homologia (SILVA; SILVA, 2007).

A ideia central no ramo estrutural da Bioinformática é a noção de homologia. Na Modelagem Molecular de Proteínas, considera-se o processo evolutivo da duplicação gênica (associado a mutações), que leva a certas divergências ao longo do tempo e, consequentemente, à formação de proteínas correlacionadas. Proteínas homólogas entre si, portanto, apresentam algumas diferenças com relação às suas sequências de aminoácidos, mas conservam alto grau de similaridade estrutural.

Geralmente, as etapas para obtenção de um modelo proteico virtual 3D utilizando a Modelagem por Homologia são:

1. Busca por proteínas homólogas - o primeiro passo na modelagem comparativa é a identificação de proteínas homólogas que possam servir como um molde para a construção da sequência-alvo (proteína-alvo). Para a predição de um modelo de qualidade, a escolha da proteína-molde deverá ser baseada nas estruturas resolvidas experimentalmente por Cristalografia de raios-X ou Ressonância Magnética Nuclear (RMN), que possuam uma alta resolução cristalográfica ( $<2 \AA$ ), bem como um fator $R<20 \%$ e identidade de sequência inicial $>25 \%$. Além disso, se o interesse da pesquisa é estudar o(s) sítio(s) ativo(s) da proteína modelada, recomenda-se que sejam selecionados moldes em sua forma holo, ou seja, a proteína deverá estar complexada com um ou mais ligantes. Estruturas experimentais podem ser encontradas no banco de dados do Protein Data Bank, PDB (BURLEY et al., 2017). Geralmente, é possível obter uma triagem de proteínas homólogas com a ferramenta de alinhamento local Basic Local Search Tool, BLAST (KEN, 2002).

2. Alinhamento de sequências - selecionada(s) a(s) proteína(s)-molde, é necessário realizar um alinhamento sequencial para identificar uma correlação entre os resíduos de aminoácidos de cada sequência. Se apenas uma sequência-molde é identificada devemos realizar um alinhamento do tipo pairwise (ao par). No entanto quando várias sequênciasmolde são identificadas, um alinhamento múltiplo deve ser realizado. Para o alinhamento final, softwares mais específicos que o BLAST devem ser utilizados.

3. Construção e otimização dos modelos - a construção da parte mais interna da proteína- 
DA SILVA, J. W. F.; PEREIRA, T. A.

Oportunidades da Química Teórica e Computacional para a Iniciação Científica

alvo se baseia na ideia de que a cadeia principal da proteína-molde pode ser transferida para ela, considerando as regiões estruturalmente conservadas durante o alinhamento. Os três principais métodos de construção de modelos proteicos por homologia são: (a) união de corpos rígidos; (b) segmentação ou threading; e (c) satisfação de restrições espaciais. Cada metodologia trata a construção interna, modelagem das regiões de alças e de cadeias laterais da proteína-alvo de maneira diferente, cabendo ao pesquisador analisar qual método melhor se adapta ao tipo de proteína que será modelada. Após a construção da proteína-alvo é necessário otimizá-la com um campo de força, geralmente por Mecânica Molecular. Este procedimento evita interações desfavoráveis entre átomos não-ligados, minimizando as energias dos ângulos torcionais e de ligação da macromolécula.

4. Validação dos modelos construídos - a validação consiste em obter uma qualidade geral da proteína modelada, de acordo com vários níveis de organização estrutural. Dentre os vários parâmetros que podem ser considerados para esta etapa, merecem destaque: (a) avaliação de empacotamento global; (b) identificação de erros em regiões localizadas; e (c) avaliação estereoquímica. Ainda, após essas etapas de validação, recomenda-se que sejam realizadas simulações de Dinâmica Molecular utilizando um solvente explícito sob temperatura e pressão constantes. A MD também chamada por "mecânica estatística numérica" e por "Visão de Laplace da Mecânica Newtoniana" é dita como uma conjectura do "futuro" por desenhos das forças da natureza, oportunizando conceber a visão do movimento molecular à proporcionalidade atômica. Nas simulações com MD é consentido aos átomos e às moléculas se inter-relacionarem por um período constante de tempo, possibilitando examinar a evolução dinâmica do sistema sob temperatura e pressões fixas. Nas versões mais habituais, as trajetórias são combinadas pela solução numérica das equações de movimento de Newton, ao mesmo tempo em que as forças entre as partículas e as suas energias potenciais são determinadas empregando potenciais interatômicos ou campos de força.

Quando não são encontrados moldes estruturais para a proteína-alvo o ideal é utilizar o método de previsão $a b$ initio, construindo o modelo a partir do zero. Este procedimento pode auxiliar a entender o princípio físico-químico de como as proteínas se dobram na natureza. Entretanto, a precisão da modelagem ab initio ainda é baixa e o sucesso é limitado às proteínas com menos de 100 resíduos de aminoácidos (LAZARIDIS; KARPLUS, 2000).

É importante destacar que existem erros associados aos métodos de Modelagem de Proteínas, como na construção das cadeias laterais, quando o grau de identidade da proteína-alvo e da proteína-molde é baixo ou quando ocorrem erros ligados ao(s) alinhamento(s). Assim, é necessário analisar e comparar parâmetros experimentais para a obtenção de um modelo de qualidade.

A quantidade de softwares e de servidores disponíveis para se trabalhar com modelagem de proteínas é bastante extensa. Uma lista resumindo os mais comuns pode ser consultada na tabela 2. 
DA SILVA, J. W. F.; PEREIRA, T. A.

Oportunidades da Química Teórica e Computacional para a Iniciação Científica

Tabela 2 - Uma lista de softwares e de servidores disponíveis para o trabalho com modelagem de proteínas.

\begin{tabular}{|c|c|c|c|}
\hline NOME & $\mathbf{T}$ & L & URL \\
\hline \multicolumn{4}{|l|}{ Banco de dados } \\
\hline PDB & D & $\boldsymbol{\square}$ & www.rcsb.org/ \\
\hline GenBank & $\mathbf{0}$ & - & www.ncbi.nlm.nih.gov/genbank/ \\
\hline ModBase & (D) & घ & www.modbase.compdio.ucsf.edu \\
\hline Uniprot & D & $\mathbf{\square}$ & www.ebi.ac.uk/uniprot \\
\hline \multicolumn{4}{|l|}{$\begin{array}{l}\text { Alinhamento de } \\
\text { sequências }\end{array}$} \\
\hline BLAST & D & $\mathbf{\square}$ & https://blast.ncbi.nlm.nih.gov/Blast.cgi \\
\hline FASTA & D & $\mathbf{\square}$ & www.ebi.ac.uk/Tools/sss/fasta/ \\
\hline Clustal & $\mathbf{D}$ & $\mathbf{\square}$ & www.ebi.ac.uk/Tools/msa/ \\
\hline \multicolumn{4}{|l|}{$\begin{array}{l}\text { Modelagem de } \\
\text { proteínas }\end{array}$} \\
\hline SWISS-MODEL & (D & घ & https://swissmodel.expansy.org/ \\
\hline MODELLER & $\diamond$ & $\mathbf{\square}$ & https://salilab.org/modeller/ \\
\hline I-TASSER & $\mathbf{D}$ & घ & https://zhanglab.ccmb.med.umich.edu/I-TASSER/ \\
\hline IntFOLD & $\mathbf{D}$ & घ & www.reading.ac.uk/bioinf/intFOLD/ \\
\hline Robetta & $\mathbf{D}$ & $\mathbf{\square}$ & http://robetta.bakerlab.org/ \\
\hline \multicolumn{4}{|l|}{ Validação } \\
\hline PROCHECK & $\diamond$ & $\boldsymbol{\square}$ & www.ebi.ac.uk/thornton-srv/software/PROCHECK/ \\
\hline WHAT_CHECK & $\bullet$ & $\mathbf{\square}$ & https://swift.cmbi.umcn.nl/gv/whatcheck/ \\
\hline Verify 3D & D & $\mathbf{\square}$ & http://servicesn.mbi.ucla.edu/Verify3D/ \\
\hline \multicolumn{4}{|l|}{$\begin{array}{l}\text { Busca por sítios } \\
\text { ativos }\end{array}$} \\
\hline metaPocket 2.0 & D & $\mathbf{\square}$ & http://projects.biotec.tu-dresden.de/metapocket/ \\
\hline metaPPI 2.0 & $\mathbf{D}$ & घ & http://projects.biotec.tu-dresden.de/metappi/ \\
\hline Deepsite & (D) & $\mathbf{\square}$ & www.playmolecule.org/deepsite/ \\
\hline \multicolumn{4}{|c|}{ Dinâmica Molecular } \\
\hline \multicolumn{4}{|c|}{ GROMACS } \\
\hline NAMD & $\diamond$ & $\mathbf{\square}$ & www.gromacs.org/ \\
\hline LAMMPS & $\bullet$ & घ & www.ks.uiuc.ed/Research/namd/ \\
\hline CHARMM & $\bullet$ & $\mathbf{\square}$ & https://lammps.sandia.gov/ \\
\hline Amber & $\diamond$ & $\mathbf{\square}$ & www.charmm.org/charmm/ \\
\hline SystemBuilder & $\diamond$ & घ & http://ambermd.org/ \\
\hline & $\mathbf{D}$ & $\mathbf{\square}$ & www.playmolecule.org/SystemBuiilder/ \\
\hline
\end{tabular}

Legenda: (T) Tipo; (L) Licença; (O) Servidor; (\$) Softwares; (E) Grátis para uso acadêmico.

3.3.3 Estudo piloto 2 - Modelagem de uma proteína de ligação a odorantes do mosquito Culex quinquefasciatus

O estudo piloto do segundo dia teve como base a modelagem de uma proteína de ligação a odorantes (do inglês, Odorant Binding Protein, OBP) do mosquito Culex quinquefasciatus (abreviatura CquiOBP1). Esta proteína foi selecionada, especificamente, pelo pouco número de estudos relacionados e, consequentemente, poderia servir como motivação para o desenvolvimento 
DA SILVA, J. W. F.; PEREIRA, T. A.

Oportunidades da Química Teórica e Computacional para a Iniciação Científica

de projetos futuros. A importância de modelar OBP de insetos está no fato de que estas proteínas atuam diretamente no primeiro nível do olfato desses organismos na seleção de semioquímicos (moléculas odorantes), contribuindo para o processo da quimiorrecepção (PELOSI; MAIDA, 1995). Atrelado a isso, é possível identificar substâncias candidatas a feromônios e a repelentes através de um método computacional conhecido como Docking Molecular (Seção 3.4.1). O reconhecimento de potenciais semioquímicos para diferentes espécies de insetos é crucial para a compreensão dos mecanismos de ligação e de liberação de odorantes em OBPs, e tem inúmeras aplicações em gestão vetorial, em controle integrado de pragas (MIP), bem como na produção de repelentes mais acessíveis e eficazes (PELOSI et al., 2014).

Pouco mais de 20 estruturas experimentais de OBP estão depositadas nos bancos de dados de proteínas. A título de ilustração, a CquiOBP1 é a única proteína do mosquito Culex quinquefasciatus com estrutura cristalográfica resolvida até o momento (MAO et al., 2010). No entanto, Manoharan et al. (2013) identificaram 113 OBP associadas ao sistema olfativo desse inseto, todas ainda sem estrutura terciária definida. 0 objetivo do estudo piloto, portanto, foi modelar uma das OBPs a fim de identificar dois possíveis semioquímicos para a espécie Culex via Docking Molecular no terceiro e último estudo piloto.

As etapas de modelagem da estrutura proteica virtual da OBP seguiram os moldes dos passos da Modelagem de Proteínas por Homologia da seção 3.3.2:

Busca pela sequência primária da proteína-alvo - os alunos tiveram acesso ao material suplementar do trabalho de Manoharan et al. (2013), em que continha todas as sequências primárias em formato fasta das OBP dos mosquitos Anopheles gambiae, Aedes aegypti e Culex quinquefasciatus. Foi selecionada a proteína CquiOBP5 com 143 aminoácidos por ser bastante similar a CquiOBP1 e, supostamente, também pode transportar o feromônio de oviposição MOP (JIAO, 2015).

Procurando a proteína-molde - a sequência primária de CquiOBP5 foi copiada em formato fasta e colada na caixa de texto da ferramenta on-line Blastp (MAHRAM; HERBORDT, 2010) para a busca de proteínas homólogas não-redundantes. Foram encontradas duas possíveis estruturas-molde com $40 \%$ e $39 \%$ de identidade sequencial, que correspondem à AgamOBP1 (2ERB) do mosquito Anopheles gambiae e à AaegOBP1 (3K1E) do mosquito Aedes aegypti, respectivamente.

Modelando a proteína - na ferramenta on-line SWISS-MODEL (SCHWEDE et al., 2003), a estrutura 3D da proteína foi modelada de acordo com os seguintes passos: a sequência foi copiada na caixa de diálogo "Start a New Modelling Project" e o título do trabalho renomeado para "Protein CquiOBP5". Após os resultados da busca em "Search For Templates", foi selecionada a proteína AaegOBP1 (3K1E) para a construção do modelo, pois estava armazenada na base de dados em sua forma holo, ao contrário da AgamOBP1 (2ERB). Além disso, a estrutura atendia aos padrões requeridos para a obtenção de um modelo virtual de qualidade, isto é, resolução 
DA SILVA, J. W. F.; PEREIRA, T. A.

Oportunidades da Química Teórica e Computacional para a Iniciação Científica

cristalográfica de $1,85 \AA$, fator $R$ de $15 \%$ e identidade de sequência inicial de 39 40\%. Ao clicar na opção "Builder Model”, o algoritmo implementado na ferramenta realizou o alinhamento necessário e gerou o modelo tridimensional requerido.

Validação do modelo - os parâmetros de validação considerados foram baseados nos próprios algoritmos implementados no SWISS-MODEL que entregam a estimativa da qualidade global do modelo construído, o GMQE e o QMEAN.

Discussão - por fim, os resultados obtidos foram analisados em conjunto com a turma, em que os discentes puderam perceber a aplicação direta do método de Modelagem de Proteínas por Homologia em uma situação-problema.

A sequência da proteína-alvo obtida do trabalho de Manoharan et al. (2013) representada na figura 4 em formato fasta contém 143 aminoácidos (aa).

Figura 4 - Sequência de aminoácidos em formato fasta da CquiOBP5.

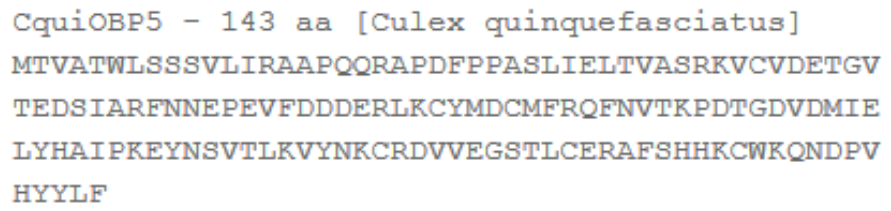

Fonte: Adaptado de Monaharan et al. (2013).

A figura 5 representa o modelo virtual 3D da CquiOBP5 gerado no SWISS-MODEL a partir da proteína-molde AaegOBP1 complexada com PEG, bem como o alinhamento de sequências necessário para a modelagem. 0 tempo para a construção do modelo foi de aproximadamente, $20 \mathrm{~s}$. Os valores correspondentes de GMQE e de QMEAN foram 0,69 e -0,99, respectivamente, refletindo a confiabilidade do modelo construído. A qualidade estimada de cada resíduo, assim como a comparação com estruturas cristalográficas resolvidas não-redundantes é mostrada na Figura 6. Após a análise dos resultados com a turma, o projeto foi baixado em formato zip para uma pasta na área de trabalho do computador dedicada ao minicurso. Os arquivos de saída da proteína-alvo, em formato $p d b$, foram, então, visualizados utilizando os softwares Jmol e Discovery Studio Visualizer (BIOVIA, 2015).

Ao final do processo de modelagem, os discentes perguntaram se seria possível melhorar a qualidade do modelo construído com alguma outra técnica computacional, demonstrando que, até este ponto, houve atenção nas abordagens dos tópicos e na execução das atividades propostas. Nesse caso, poderia ter sido realizada uma simulação de Dinâmica Molecular com campo de força ou otimização de geometria por métodos semiempíricos. Contudo, para fins didáticos foi mostrado apenas como os arquivos de entrada para esses dois métodos podem ser preparados, uma vez que simulações de MD e de SE para proteínas demandam muito tempo computacional. 
DA SILVA, J. W. F.; PEREIRA, T. A.

Oportunidades da Química Teórica e Computacional para a Iniciação Científica

Figura 5 - Proteína-alvo CquiOBP5 modelada; (B) Proteínas-molde AaegOBP1; (C) Alinhamento executado pelo SWISS-MODEL.

A

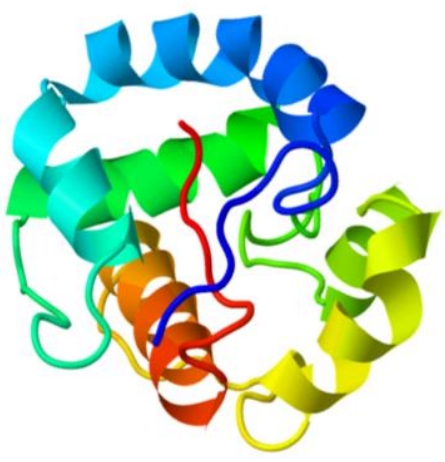

C
B
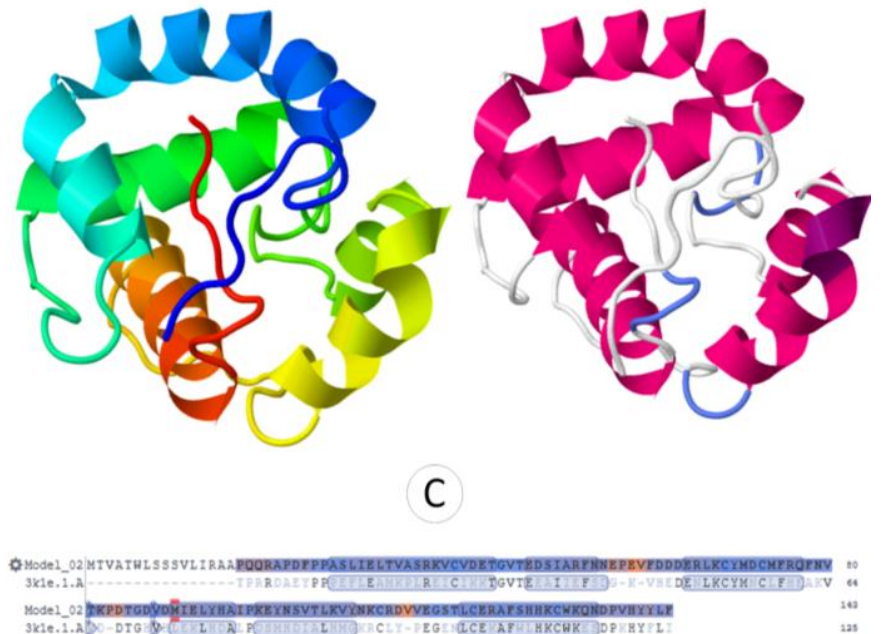

Fonte: Dos autores.

Figura 6 - (A) Estimativa da qualidade local de cada resíduo modelado; (B) Comparação da qualidade do modelo construído com estruturas cristalográficas depositadas no PDB; Pontuações mais altas indicam maior confiabilidade.

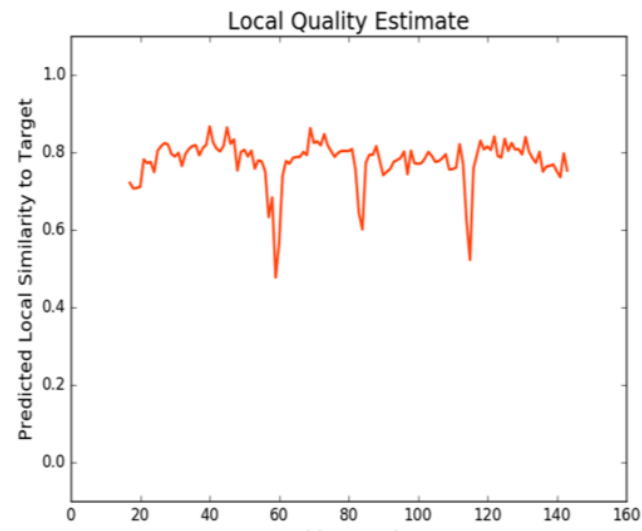

A

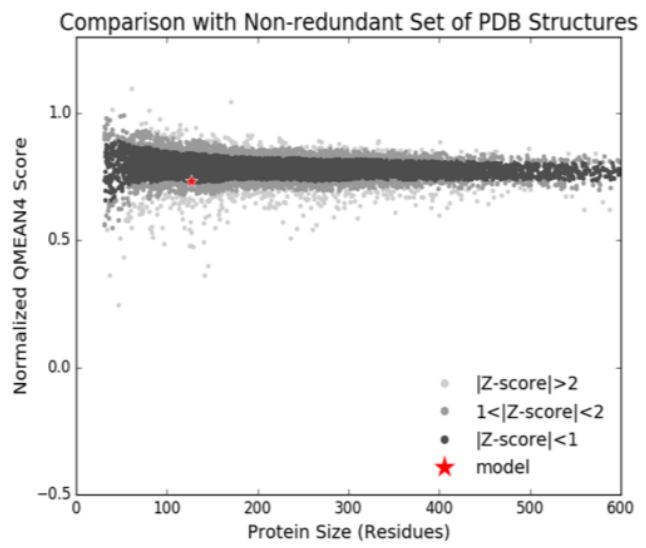

B

Fonte: Dos autores. 
DA SILVA, J. W. F.; PEREIRA, T. A.

Oportunidades da Química Teórica e Computacional para a Iniciação Científica

\subsection{Terceiro dia}

\subsubsection{Docking Molecular}

A tradução para Docking é encaixe, uma metodologia que auxilia na descrição in silico das interações químicas entre uma pequena molécula (comumente chamada de ligante) e uma biomolécula (proteína, comumente chamada de receptor) em seu sítio de ligação, permitindo elucidar processos bioquímicos fundamentais (Fig. 7). Métodos de Docking são intensamente utilizados para a descoberta de novos medicamentos para o combate de doenças humanas (MENG et al., 2011).

Realizar estudos de acoplamento proteína-ligante (complexo proteico) é relativamente simples. Geralmente, esse processo envolve duas etapas fundamentais: (1) a previsão da pose (conformação) do ligante no local do sítio de ligação da proteína; e (2) avaliação da afinidade de ligação (score). Uma prática bastante comum entre os pesquisadores que trabalham com Docking é conhecer o sítio de ligação do receptor previamente, a fim de facilitar o algoritmo de busca das conformações mais favoráveis do ligante. Quando este parâmetro não é determinado e, consequentemente, não há nenhuma suposição sobre o sítio de ligação o método é chamado de Docking Cego (TAYLOR; JEWSBURY; ESSEX, 2002).

O primeiro modelo para elucidar o mecanismo de ação proteína-ligante foi proposto por Fischer. Neste, tanto o receptor quanto o ligante são tratados como corpos rígidos (modelo "chave e fechadura"). No entanto, sabemos que sistemas biológicos são complexos e dinâmicos, portanto esse modelo não é o ideal para representar simulações realistas. Então a teoria de "ajuste induzido" criada por Koshland dá um upgrade ${ }^{1}$ nas ideias de Fischer, afirmando que o sítio de ligação da proteína pode ser continuamente reformulado por interações com os ligantes, sugerindo que tanto o receptor quanto o ligante devam ser tratados como flexíveis durante o Docking.

Os métodos de Docking podem ser escolhidos considerando o poder computacional disponível e a natureza da pesquisa. Quando os elementos do sistema são tratados como corpos rígidos, o espaço de busca é bastante limitado, ficando restrito para três graus de liberdade rotacionais e para três graus de liberdade translacionais, o que exige menos recurso computacional. Existe a possibilidade de considerar o ligante flexível e a proteína rígida, um método mais comumente utilizado por fornecer ótimos resultados em máquinas que possuem processamento limitado. Todavia, incorporar a flexibilidade no receptor ainda é um desafio no campo do Docking. Alternativamente, poderíamos obter todos os graus de liberdade do complexo proteína-ligante utilizando simulações de Dinâmica Molecular, no entanto, o alto custo computacional envolvido promove limitações para a análise de grandes bancos de dados químicos. Felizmente, aos poucos, algoritmos vêm sendo desenvolvidos para a inclusão da flexibilidade do receptor. Um deles é o softdocking, que ajusta alguns parâmetros das interações de van der Waals, como o termo da energia de 
DA SILVA, J. W. F.; PEREIRA, T. A.

Oportunidades da Química Teórica e Computacional para a Iniciação Científica

repulsão, possibilitando maior eficiência computacional (JIANG; KIM, 1991). A Fig. 7 representa como ocorre a formação de um complexo proteico por meio do Docking.

Figura 7 - Formação de um complexo proteico durante o Docking Molecular. Nesta representação, a proteína é a CquiOBP1 e o ligante correspondente é o feromônio de oviposição MOP. É possível notar que o ligante se encaixa em um túnel dentro da proteína.

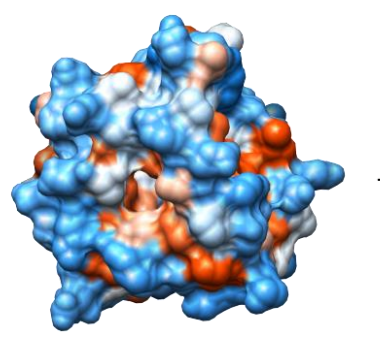

Proteína
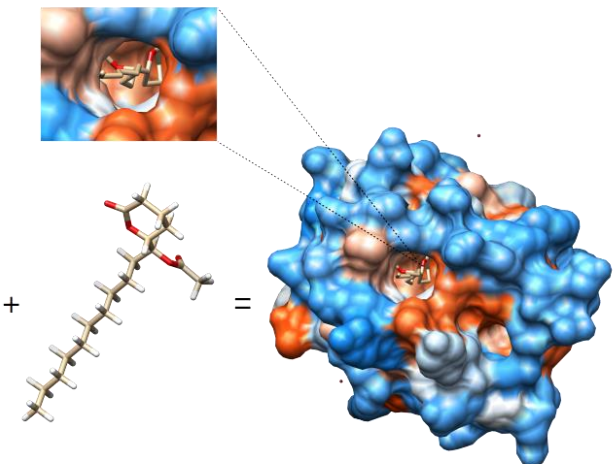

Complexo

Fonte: Dos autores.

\subsubsection{Estudo piloto 3 - Docking Molecular com Autodock Vina}

O último estudo piloto do minicurso teve como base a execução de Docking Molecular em um software livre conhecido como Autodock Vina (TROTT; OLSON, 2010), que está entre os mais usados dentre a comunidade científica. Para esta etapa, os discentes receberam um pequeno guia com os comandos básicos necessários para a simulação.

Para que houvesse uma lógica de estudo sequencial, o receptor considerado foi a proteína CquiOBP5 modelada anteriormente. A seleção dos ligantes ocorreu por meio de consulta prévia da literatura, mais especificamente no artigo de Jiao et al. (2015). Os autores relataram em seu trabalho que, de acordo com as constantes de dissociação obtidas por ensaio de fluorescência para um painel de 34 compostos, as proteínas CquiOBP1 e CquiOBP5 possuem alta afinidade de ligação com o feromônio de oviposição MOP e o repelente de insetos Icaridina. Assim, o objetivo do estudo piloto 3 foi obter a afinidade de ligação para CquiOBP1 e para CquiOBP5 com esses dois compostos, de acordo com os seguintes procedimentos:

1. Procurando por sítios ativos nas proteínas - a fim de reduzir custo computacional, utilizouse a ferramenta on-line Deepsite para a identificação dos possíveis sítios de ligação para CquiOBP1 e CquiOBP5. Os arquivos de entrada em formato pdb foram devidamente preparados no Discovery Studio Visualizer, em que os íons e as moléculas de água foram removidos de ambos os sistemas.

2. Preparação dos ligantes - foi realizada uma busca pelas estruturas dos ligantes no banco de 
DA SILVA, J. W. F.; PEREIRA, T. A.

Oportunidades da Química Teórica e Computacional para a Iniciação Científica

dados de moléculas orgânicas, PubChem, consoante com a nomenclatura recomendada pela IUPAC: Icaridin e (5R,6S)-6-acetoxy-5-hexadecanolide (MOP). As estruturas foram construídas manualmente pelos alunos em 2D no software ChemSketch e convertidas em 3D no Avogadro. As cargas parciais e otimização de geometria dos compostos foram obtidas no MOPAC/2016 de acordo com hamiltoniano RM1 e com o método de otimização padrão EF.

3. Preparação dos arquivos de entrada para o Docking - utilizando o software livre Autodock Tools (HUEY; MORRIS, 2003), os arquivos de entrada para o Autodock Vina foram preparados em formato pdbqt e um arquivo nomeado de conf.txt contendo as coordenadas do sítio de ligação das proteínas individuais foi criado no Bloco de Notas.

4. Obtenção dos resultados - o executável [vina.exe --config conf.txt --log log.txt] do Autodock Vina devolveu as energias de interação para os compostos com as proteínas. Os arquivos de visualização 3D foram gerados com o comando vina_split --input out.pdbqt.

Os resultados obtidos do Deepsite representam as coordenadas cartesianas em 3 dimensões do principal sítio de ligação das proteínas. Para CquiOBP1 e para CquiOBP5, as regiões mais favoráveis para o Docking Molecular se concentraram no centro da proteína, o que está de acordo com a literatura. Os valores correspondentes para CquiOBP1 foram $x=-1.1, y=27.8, z=9.3$, e para CquiOBP5 foram $x=12.0, y=41.8, z=23.3$. As estruturas otimizadas do MOP e da Icaridina, assim como as propriedades estruturais e eletrônicas podem ser consultadas na Fig. 8.

Os valores de Docking obtidos do Autodock Vina foram favoráveis, indicando que a energia livre de ligação também é um fator crucial para a interação CquiOBP-odorantes, além das constantes de dissociação (JIAO et al., 2015). Em resumo, os resultados de energia livre de ligação para CquiOBP1 com os ligantes Icaridina e MOP foi de $-6,5$ e de $-7,8 \mathrm{kcal} / \mathrm{mol}$, respectivamente, enquanto que para CquiOBP5 foi de $-4,9$ e de $-6,7 \mathrm{kcal} / \mathrm{mol}$, nesta ordem. As poses conformacionais com melhor score foram visualizadas no Discovery Studio Visualizer, bem como a natureza das interações químicas provenientes do Docking. 
DA SILVA, J. W. F.; PEREIRA, T. A.

Oportunidades da Química Teórica e Computacional para a Iniciação Científica

Figura - Estruturas otimizadas em RM1 do repelente de insetos icaridina e do feromônio de oviposição MOP. As esferas em cinza, em azul, em vermelho e em branco representam os átomos de carbono $(C)$, de nitrogênio $(N)$, de oxigênio $(O)$ e de hidrogênio $(H)$.
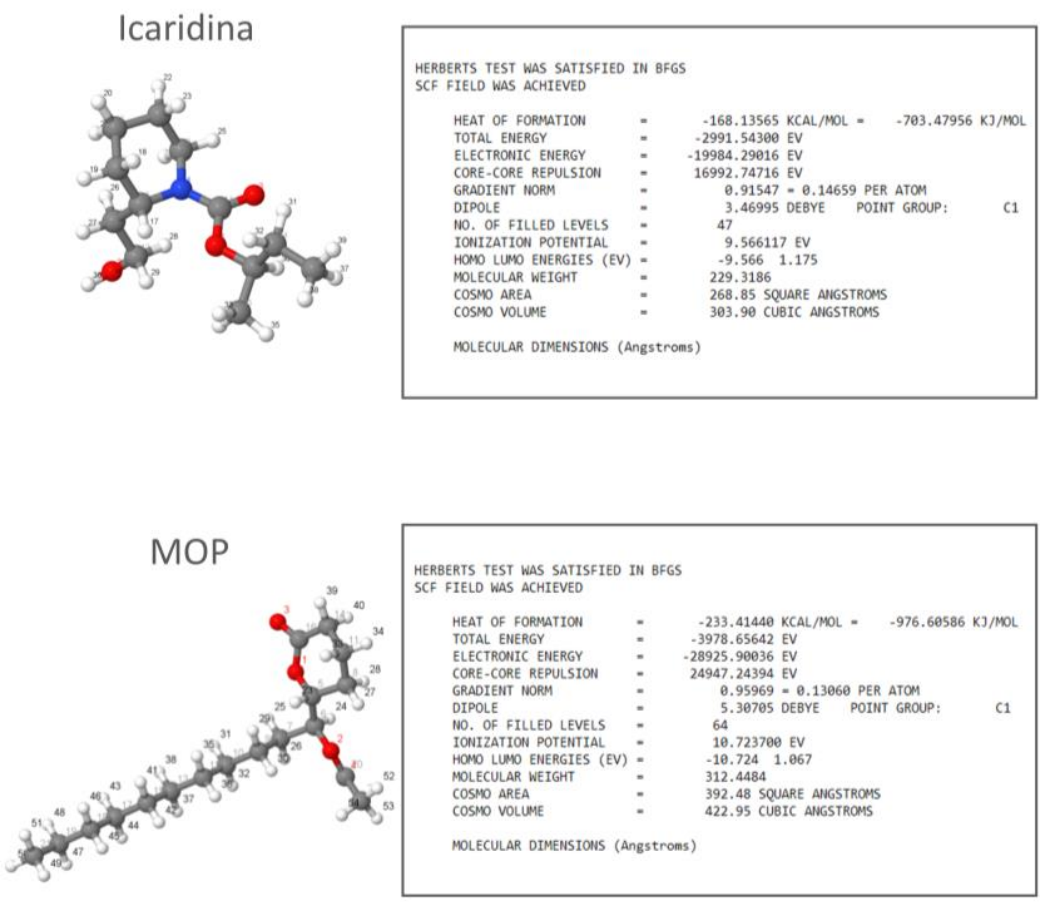

Fonte: Dos autores.

\subsubsection{Percepções sobre o minicurso e comentários gerais}

De acordo com sequência metodológica adotada para a abordagem de todos os tópicos e a avaliação geral dos alunos (Tabela 3), considera-se que os objetivos do minicurso foram atingidos. Resultados positivos foram observados no decorrer do minicurso em relação a não aversão pela área, apesar de poucos conhecerem antes de se inscreverem. Isso corrobora que a inclusão de estudospiloto em Química Teórica e Computacional pode tanto propiciar a aprendizagem de conceitos químicos abstratos, como também despertar a motivação para o desenvolvimento de projetos científicos.

Em média, cerca de $70 \%$ dos participantes desconheciam o âmbito de estudo, com uma porcentagem de 100\% para os estudantes do Ensino Médio e de $42,9 \%$ para os estudantes de Licenciatura em Química. Estes resultados corroboram os estudos realizados por Santos e Silva (2020) que destacam uma produção mínima de trabalhos voltados para a inserção de simulações computacionais/Modelagem Molecular no ensino. Na prática, conceitos introdutórios da área, poderiam ser discutidos por meio de projetos, de palestras, de rodas de conversa ou, até mesmo, de minicursos organizados por um docente.

Ainda, $100 \%$ dos participantes avaliaram os conteúdos abordados como bom, ótimo ou excelente e o percentual de $97,5 \%$ relatou ter havido clareza e objetividade na explicação. Naturalmente, os graduandos em Química se interessam mais pelo campo de pesquisa do que os 
DA SILVA, J. W. F.; PEREIRA, T. A.

Oportunidades da Química Teórica e Computacional para a Iniciação Científica

demais alunos do Ensino Médio e Técnico Subsequente. Isso porque quando foram questionados se pretendiam aplicar algum conhecimento de Química Teórica e Computacional em pesquisas científicas, 57,1\% responderam que sim, 28,5\% que talvez, e 14,4\% que ainda não haviam pensado nisso. Por outro lado, apenas $12,5 \%$ dos discentes do Ensino Médio se interessaram pela área e não pretendiam aplicar esse conhecimento em pesquisas ou ainda não haviam pensado a respeito. Curiosamente, $87,5 \%$ dos alunos do curso técnico se interessaram pelo campo, o que pode ser justificado pelo fato da maioria pertencer ao curso de Informática do campus.

Felizmente, a vivência do minicurso culminou o registro de três projetos científicos voluntários na área de Química Teórica e Computacional com ênfase em rastreamento in silico de semioquímicos, em supercondutividade e em catálise enzimática de azocorantes. Interessantemente, foram os próprios alunos do curso de Licenciatura em Química que escreveram as propostas dos projetos para a coordenação de pesquisa do IF Sertão Pernambucano - Campus Ouricuri.

É evidente que a Química Teórica e Computacional, bem como áreas correlacionadas ensejam inúmeras possibilidades para o ingresso no campo da Iniciação Científica em qualquer nível de ensino. Este aspecto é facilitado devido à evolução tecnológica e à variedade de softwares e de servidores de código aberto atualmente disponíveis. Em contrapartida, percebe-se que os ramos da Química Teórica e Computacional ainda são pouco difundidos na comunidade científica brasileira, tendo em vista a carência de periódicos específicos e a pequena quantidade de artigos em português. Por sua vez, a não inclusão de disciplinas fundamentais para a compreensão de conceitos aprimorados de Mecânica Quântica no Ensino Superior, por exemplo, torna o trabalho com sistemas químicos a nível atômico e molecular uma possibilidade apenas em cursos de Pós-Graduação.

Assim, a inserção de cursos de Extensão Universitária em momentos oportunos da vida escolar ou da vida acadêmica dos alunos poderia funcionar como ponto de partida para o desenvolvimento de projetos científicos originais em Química Teórica e Computacional, contribuindo também para a divulgação da área. A proposta de minicurso apresentada neste trabalho pode servir como modelo, no que tange às práticas computacionais dos estudos-piloto, para a implementação e para a ampliação em trabalhos futuros. 
DA SILVA, J. W. F.; PEREIRA, T. A.

Oportunidades da Química Teórica e Computacional para a Iniciação Científica

Tabela 3 - Percepções e avaliações do minicurso.

\begin{tabular}{|c|c|c|c|c|c|c|}
\hline \multicolumn{7}{|c|}{ QUESTŌES } \\
\hline Curso & $1^{*}$ & 2 & 3 & 4 & 5 & 6 \\
\hline & $\begin{array}{c}\text { O que motivou a } \\
\text { inscrição no minicurso? }\end{array}$ & $\begin{array}{c}\text { Você conhecia a área de } \\
\text { Química Teórica e } \\
\text { Computacional? }\end{array}$ & $\begin{array}{l}\text { Como você avalia } \\
\text { os conteúdos } \\
\text { abordados durante } \\
\text { o minicurso? }\end{array}$ & $\begin{array}{l}\text { Houve clareza e } \\
\text { objetividade na } \\
\text { explicação dos } \\
\text { conteúdos? }\end{array}$ & $\begin{array}{c}\text { Você se } \\
\text { interessou pela } \\
\text { área? }\end{array}$ & $\begin{array}{c}\text { Pretende aplicar } \\
\text { algum conhecimento } \\
\text { de Química Teórica e } \\
\text { Computacional em } \\
\text { pesquisas científicas } \\
\text { futuramente? }\end{array}$ \\
\hline EMI & $\begin{array}{l}(12,5 \%) \text { Certificado } \\
(62,5 \%) \text { Busca por novos } \\
\text { conhecimentos } \\
(0,00 \%) \text { Aprimoramento } \\
\text { de conhecimentos } \\
(75,0 \%) \text { Curiosidade sobre } \\
\text { o tema }\end{array}$ & $\begin{array}{l}(0,00 \%) \text { Sim } \\
(100 \%) \text { Não }\end{array}$ & $\begin{array}{l}(0,00 \%) \text { Ruim } \\
(37,5 \%) \text { Bom } \\
(50,0 \%) \text { Ótimo } \\
(12,5 \%) \text { Excelente } \\
(0,00 \%) \text { Não sei }\end{array}$ & $\begin{array}{l}(87,5 \%) \text { Sim } \\
(12,5 \%) \text { Não } \\
(0,00 \%) \text { Não sei }\end{array}$ & $\begin{array}{l}(12,5 \%) \text { Sim } \\
(75,0 \%) \text { Não } \\
(12,5 \%) \text { Talvez }\end{array}$ & $\begin{array}{l}(0,00 \%) \text { Sim } \\
(37,5 \%) \text { Não } \\
(37,5 \%) \text { Talvez } \\
\text { (25,0\%) Ainda não } \\
\text { pensei nisso }\end{array}$ \\
\hline LPQ & $\begin{array}{l}(28,6 \%) \text { Certificado } \\
(100 \%) \text { Busca por novos } \\
\text { conhecimentos } \\
(14,3 \%) \text { Aprimoramento } \\
\text { de conhecimentos } \\
(85,7 \%) \text { Curiosidade sobre } \\
\text { o tema }\end{array}$ & $\begin{array}{l}(57,1 \%) \text { Sim } \\
(42,9 \%) \text { Não }\end{array}$ & $\begin{array}{l}(0,00 \%) \text { Ruim } \\
(14,9 \%) \text { Bom } \\
(00,0 \%) \text { Ótimo } \\
(85,1 \%) \text { Excelente } \\
(0,00 \%) \text { Não sei }\end{array}$ & $\begin{array}{l}(100 \%) \operatorname{Sim} \\
(0,00 \%) \text { Não } \\
(0,00 \%) \text { Não sei }\end{array}$ & $\begin{array}{l}(57,1 \%) \text { Sim } \\
(0,00 \%) \text { Não } \\
(42,9 \%) \text { Talvez }\end{array}$ & $\begin{array}{l}(57,1 \%) \text { Sim } \\
(0,00 \%) \text { Não } \\
(28,5 \%) \text { Talvez } \\
(14,4 \%) \text { Ainda não } \\
\text { pensei nisso }\end{array}$ \\
\hline TIS & $\begin{array}{l}\text { (50\%) Certificado } \\
(50 \%) \text { Busca por novos } \\
\text { conhecimentos } \\
(0,00 \%) \text { Aprimoramento } \\
\text { de conhecimentos } \\
\text { (50\%) Curiosidade sobre o } \\
\text { tema }\end{array}$ & $\begin{array}{l}(0,00 \%) \text { Sim } \\
(100 \%) \text { Não }\end{array}$ & $\begin{array}{l}(0,00 \%) \text { Ruim } \\
(75,0 \%) \text { Bom } \\
(25,0 \%) \text { Ótimo } \\
(0,00 \%) \text { Excelente } \\
(0,00 \%) \text { Não sei }\end{array}$ & $\begin{array}{l}(100 \%) \text { Sim } \\
(0,00 \%) \text { Não } \\
(0,00 \%) \text { Não sei }\end{array}$ & $\begin{array}{l}(0,00 \%) \operatorname{Sim} \\
(25,0 \%) \text { Não } \\
(75,0 \%) \text { Talvez }\end{array}$ & $\begin{array}{l}(0,00 \%) \text { Sim } \\
(0,00 \%) \text { Não } \\
(0,00 \%) \text { Talvez } \\
(100 \%) \text { Ainda não } \\
\text { pensei nisso }\end{array}$ \\
\hline
\end{tabular}

$(0,00 \%)$ Certificado (100\%) Busca por novos conhecimentos

(0,00\%) Ruim

$(0,00 \%) \mathrm{Sim}$ (100\%) Não de conhecimentos (100\%) Curiosidade sobre o tema

$(0,00 \%)$ Bom
$(00,0 \%)$ Ótimo
$(100 \%)$ Excelente

$(0,00 \%)$ Não sei
$(100 \%) \operatorname{Sim}$

$(0,00 \%)$ Não

$(0,00 \%)$ Não sei

(100\%) Sim

$(0,00 \%)$ Não

$(0,00 \%)$ Talvez
(0,00\%) Sim

$(0,00 \%)$ Não

$(0,00 \%)$ Talvez

(100\%) Ainda não pensei nisso

$(0,00 \%)$ Certificado

(100\%) Busca por novos

conhecimentos

PRO

(0,00\%) Aprimoramento

de conhecimentos

$(0,00 \%)$ Curiosidade sobre

o tema

(0,00\%) Ruim

$(0,00 \%)$ Bom

$(00,0 \%)$ Ótimo

(100\%) Excelente

$(0,00 \%)$ Não sei

\section{$(100 \%) \mathrm{Sim}$ \\ $(0,00 \%)$ Não \\ $(0,00 \%)$ Não sei \\ $(100 \%) \operatorname{Sim}$ \\ $(0,00 \%)$ Não}

$(0,00 \%)$ Não

$(0,00 \%)$ Talvez

$(0,00 \%)$ Ainda não

pensei nisso

Legenda: *Questão de múltipla escolha; (EMI) Ensino Médio Integrado ao Técnico em Informática; (LPQ) Licenciatura Plena em Química; (TIS) Técnico em Informática - Subsequente; (TED) Técnico em Edificações - Subsequente; (PRO) Professor. 
DA SILVA, J. W. F.; PEREIRA, T. A.

Oportunidades da Química Teórica e Computacional para a Iniciação Científica

\section{Conclusão}

O presente trabalho apresenta a vivência de um minicurso com foco na divulgação da Química Teórica e Computacional e da importância da Iniciação Científica no âmbito da educação formal. O minicurso foi projetado para destacar os aspectos práticos da Química Computacional em conjunto com a Modelagem Molecular, a fim de gerar discussões acerca das inúmeras oportunidades que esse campo pode oferecer ao desenvolvimento de projetos científicos originais.

Os estudos-piloto foram pensados a partir de aplicações diretas sobre estudos recentes, com o intuito de abranger parte dos conceitos da Mecânica Quântica que, no que lhe concerne, são primordiais para uma interpretação adequada dos resultados provenientes dos softwares de Química Computacional. Houve uma aceitação positiva do público participante, principalmente dos alunos do curso superior de Licenciatura em Química, em relação aos conteúdos abordados.

Por fim, um dos resultados mais satisfatórios deste trabalho é que o minicurso serviu como motivação para o registro de três projetos científicos voluntários na área de Química Teórica e Computacional na Coordenação de Pesquisa do IF Sertão Pernambucano - Campus Ouricuri.

\section{Referências}

ACD/ChemSketch, version 2.1, Advanced Chemistry Development, Inc., Toronto, ON, Canada, www.acdlabs.com, 2015.

ANIKIN, N. A.; ANISIMOV, V. M.; BUGAENKO V. L.; BOBRIKOV V. V.; ANDREYEV, A. M. LocalSCF method for semiempirical quantum-chemical calculation of ultralarge biomolecules. The Journal of Chemical Physics, v. 121, n. 3, p. 1266-1270, 2004.

BAKER, J. An algorithm for the location of transition states. Journal of Computational Chemistry, v. 7, n. 4, p. 385-395, 1986.

BIOVIA, Dassault Systemes. BIOVIA Discovery Studio Visualizer, v16. 1.0. 15350, San Diego: Dassault Systemes; 2015 [cited: 2018 Dez 30].

BRASIL, Ministério da Ciência e Tecnologia. Conselho Nacional de Desenvolvimento Científico e Tecnológico. Anexo III da RN-017/2006: bolsas por quota no país; Pibic - norma específica. 2007. Disponível em: <http://www.cnpq.br/web/guest/view//journal_content/56_INSTANCE_OoED/10157/100352> Acesso em: 18 jun. 2018.

BURLEY, Stephen K. et al. Protein Data Bank (PDB): the single global macromolecular structure archive. In: Protein Crystallography. Humana Press, New York, NY, 2017. p. 627-641.

CAPARLAR, C. Ö.; DÖNMEZ, A. What is scientific research and how can it be done? Turk J Anaesthesiol Reanim, v. 44, n. 4, p. 212-218, 2012.

CENAPAD-SP. Institucional: sobre o CENAPAD-SP. 2018a. Disponível em: <https://www.cenapad.unicamp.br/home/maim.shtml>Acesso em: 16 dez. 2018.

CENAPAD-SP. Publicações: produção científica. 2018b. Disponível em: <https://www.cenapad.unicamp.br/diversos/prod_cient/prod_cient.shtml> Acesso em: $16 \mathrm{dez}$. 2018.

FELLER, S. E.; DALLINGER, R. F.; MCKINNEY, P. C. A program of computational chemistry exercises for 
DA SILVA, J. W. F.; PEREIRA, T. A

Oportunidades da Química Teórica e Computacional para a Iniciação Científica

the first-semester general chemistry course. Journal of Chemical Education, v. 81, n. 2, p. 283-287, 2004.

FROIMOWITZ, M. Hyperchem: a software package for computational chemistry and molecular modeling. Biotechniques, v. 14, n. 6, p. 1010-1013, 1993.

Gaussian 16, Revision B.01, FRISCH, M. J.; TRUCKS, G. W.; SCHLEGEL, H. B.; SCUSERIA, G. E.; ROBB, M. A.; CHEESEMAN, J. R.; SCALMANI, G.; BARONE, V.; PETERSSON, G. A.; NAKATSUJI, H.; LI, X.; CARICATO, M.; MARENICH, A. V.; BLOINO, J.; JANESKO, B. G.; GOMPERTS, R.; MENNUCCI, B.; HRATCHIAN, H. P.; ORTIZ, J. V.; IZMAYLOV, A. F.; SONNENBERG, J. L.; WILLIAMS-YOUNG, D.; DING, F.; LIPPARINI, F.; EGIDI, F.; GOINGS, J.; PENG, B.; PETRONE, A.; HENDERSON, T.; RANASINGHE, D.; ZAKRZEWSKI, V. G.; GAO, J.; REGA, N.; ZHENG, G.; LIANG, W.; HADA, M.; EHARA, M.; TOYOTA, K.; FUKUDA, R.; HASEGAWA, J.; ISHIDA, M.; NAKAJIMA, T.; HONDA, Y.; KITAO, O.; NAKAI, H.; VREVEN, T.; THROSSELL, K.; MONTGOMERY, J. A., JR.; PERALTA, J. E.; OGLIARO, F.; BEARPARK, M. J.; HEYD, J. J.; BROTHERS, E. N.; KUDIN, K. N.; STAROVEROV, V. N.; KEITH, T. A.; KOBAYASHI, R.; NORMAND, J.; RAGHAVACHARI, K.; RENDELL, A. P.; BURANT, J. C.; IYENGAR, S. S.; TOMASI, J.; COSSI, M.; MILLAM, J. M.; KLENE, M.; ADAMO, C.; CAMMI, R.; OCHTERSKI, J. W.; MARTIN, R. L.; MOROKUMA, K.; FARKAS, O.; FORESMAN, J. B.; FOX, D. J. Gaussian, Inc., Wallingford CT, 2016.

HANWELL, M.; CURTIS, D. E.; LONIE, D. C.; VANDERMEERSCH, T.; ZUREK, E.; Avogadro: an advanced semantic chemical editor, visualization, and analysis platform. Journal of cheminformatics, v. 4, n. 1, p. 17, 2012.

HARTREE, D. R. The wave mechanics of an atom with a non-Coulomb central field. Part I, II e III. Mathematical Proceeding of the Cambridge Philosophical Society, v. 24, n. 1 a 3, p. 89-437, 1928.

HEHRE, W. J.; YU, J.; KLUNZINGER, P. E.; LOU, L. Spartan Software. Wavefunction. Inc., Irvine, 2000.

HEISENBERG, W. Über den anschaulichen inhalt der quantentheoretischen kinematik und mechanik. Zeitschrift für Physik, v. 43, n. 3-4, p. 172-198, 1927.

HUEY, R.; MORRIS, G. M. AutoDock tools. La Jolla, CA, USA: The Scripps Research Institute, 2003.

HUNTER, A-B; LAURSEN, S. L; SEYMOUR, E. Becoming a scientist: the role of undergraduate research in students' cognitive, personal, and professional development. Science Education, v. 91, n. 1, p. 36-74, 2006.

Hypescience. Estranho mapa do mundo baseado na produção científica. Disponível em: <https://hypescience.com/mapa-mundo-ciencia-producao-cientifica/> Acesso em 16 nov. 2018.

IUPAC. Glossary of terms used in medicinal chemistry (IUPAC Recommendations 1998). Pure \& Appl. Chem., v. 70, n. 5, p. 1129-1143, 1998.

JIANG, F.; KIM, S-H. "Soft docking": matching of molecular surface cubes. Journal of Molecular Biology, v. 219, n. 1, p. 79-102, 1991.

JIAO, Y.; YOUNG-MOO, C.; DUAN, H.; LEAL, W. S. Selectivity of odorant-binding-proteins from the southern house mosquito tested against physiologically relevant ligands. Frontiers Physiology, v. 6, n. 56, 2015. doi: 10.3389/fphys.2015.00056.

Jmol: an open-source Java viewer for chemical structures in 3D. Disponível em: <http://www.jmol.org/> Acesso em: 26 dez. 2018.

KENT, W. J. BLAT-the BLAST-like alignment tool. Genome Research, v. 12, n. 4, p. 656-664, 2002.

KIM, S.; THIESSEN, P. A.; BOLTON, E. E.; CHEN, J.; FU, G.; GINDULYTE, A.; WANG, J. PubChem substance and compound databases. Nucleic Acids Research, v. 44, n. D1, p. D1202-D1213, 2015.

LATOUR, B.; WOOLGAR, S. A vida de laboratório: a produção dos fatos científicos. Rio de Janeiro: 
DA SILVA, J. W. F.; PEREIRA, T. A.

Oportunidades da Química Teórica e Computacional para a Iniciação Científica

Relume Dumará, 1997.

LAZARIDIS, T.; KARPLUS, M.; Effective energy functions for protein structure prediction. Current Opinion in Structural Biology, v. 10, n. 2, p. 139-145, 2000.

LINSTROM, P. J.; MALLARD, W. G. NIST Chemistry webbook; NIST standard reference database No. 69. 2001.

LUDKE, M.; ANDRÉ, M. E. D. A. Pesquisa em educação: abordagens qualitativas. São Paulo, Editora Pedagógica e Universitária, 1986.

MAHRAM, A.; HERBORDT, M. C. Fast and accurate NCBI BLASTP: acceleration with multiphase FPGAbased prefiltering. In: Proceedings of the 24th ACM International Conference on Supercomputing. ACM, 2010. p. 73-82.

MAO, Y.; XU, X.; XU, W.; ISHIDA, Y.; LEAL, W. S.; AMES, J. B.; CLARDY, J. Crystal and solution structures of an odorant-binding protein from the southern house mosquito complexed with an oviposition pheromone. Proceedings of the National Academy of Sciences of the United States of America, v. 107, n. 44, p. 19102-19107, 2010.

MASSI, L.; QUEIROZ, S. T. Estudos sobre iniciação científica no Brasil: uma revisão. Cadernos de Pesquisa, v. 40, n. 139, p. 173-197, 2010.

MENG, X. Y.; ZHANG, H. X.; MEZEI, M.; CUI, M. Molecular docking: a powerful approach for structure-based drug discovery. Current Computer-Aided Drug Design, v. 7, n. 2, p. 146-157, 2011.

MOPAC2016, James J. P. Stewart, Stewart Computational Chemistry, Colorado Springs, CO, USA, <HTTP://OpenMOPAC.net> (2016).

MOREIRA, M. A. Modelos científicos, modelos mentais, modelagem computacional e modelagem matemática: aspectos epistemológicos e implicações para o ensino. Revista Brasileira de Ensino de Ciência e Tecnologia, v. 7, n. 2, 2014. doi: 10.3895/S1982-873X2014000200001.

NOGUEIRA, M. A.; CANNAN, M. G. Os "iniciados": os bolsistas de iniciação científica e suas trajetórias acadêmicas. TOMO, n. 15, p. 41-70, 2009.

OGLE, D. M. K-W-L: A teaching model that develops active reading of expository text. The Reading Teacher, v. 39, n. 6, p. 564-570, 1986.

PEARSON, J. K. Introducing the practical aspects of computational chemistry to undergraduate chemistry students. Journal of Chemical Education, v. 84, n. 8, p. 1323-1325, 2007.

PELOSI, P.; MAIDA, R. Odorant-binding proteins in insects. Comparative Biochemistry and Physiology Part B: Biochemistry and Molecular Biology, v. 111, n. 3, p. 503-514, 1995.

PELOSI, P.; MASTROGIACOMO, R.; IOVINELLA, I.; TUCCORI, E.; PERSAUD, K. C. Structure and biotechnological applications of odorant-binding proteins. Applied Microbiology and Biotechnology, v. 98, n. 1, p. 61-70, 2014.

PLANCK, M. Zur Theorie des Gesetzes der Energieverteilung im Normalspectrum. Verhandlungen der Deutschen Physikalischen Gesellschaft, vol. 2, p. 237-45, 1900. English translation by D. ter Haar 1967 The Old Quantum Theory (Pergamon Press).

ROCHA, G. B.; FREIRE, R. O.; SIMAS, A. M.; STEWART, J. J. P. RM1: A reparameterization of AM1 for $\mathrm{H}, \mathrm{C}, \mathrm{N}, \mathrm{O}, \mathrm{P}, \mathrm{S}, \mathrm{F}, \mathrm{Cl}, \mathrm{Br}$, and I. Journal of Computational Chemistry, v. 27, n. 10, p. 1101-1111, 2006.

RUNGE, E.; GROSS, E. K. U. Density-Functional Theory for time-dependent systems. Physical Review Letters, v. 52, n. 2, p. 997-1000, 1984. 
DA SILVA, J. W. F.; PEREIRA, T. A.

Oportunidades da Química Teórica e Computacional para a Iniciação Científica

SANCHEZ, R.; ŠALI, A. Advances in comparative protein-structure modelling. Current Opinion in Structural Biology, v. 7, n. 2, p. 206-214, 1997.

SANTOS, E. O.; SILVA, I. P. Revisão acerca do tema simulações computacionais no ensino de química (2008-2017). Debates em Educação, v. 12, n. 27, p. 841-855, 2020.

SBQT. Apresentação - Simpósio Brasileiro de Química Teórica 2017. <http://www.sbqt2017.if.usp.br/>. Acesso em 20 dez. 2018.

SCHMIDT, M. W.; BALDRIDGE, K. K.; BOATZ, J. A.; ELBERT, S. T.; GORDON, M. S.; JENSEN, J. H.; WINDUS, T. L. General atomic and molecular electronic structure system. Journal of Computational Chemistry, v. 14, n. 11, p. 1347-1363, 1993.

SCHRÖDINGER, E. An undulatory theory of the mechanics of atoms and molecules. Physical Review, v. 28, n. $6,1949-1970,1926$.

SCHWEDE, T.; KOPP, J.; GUEX, N.; PEITSCH, M. C. SWISS-MODEL: an automated protein homologymodeling server. Nucleic acids research, v. 31, n. 13, p. 3381-3385, 2003.

SHAO, Y. et al. Advances in molecular quantum chemistry contained in the Q-Chem 4 program package. Molecular Physics, v. 113, n. 2, p. 184-215, 2015.

SILVA, V. B.; SILVA, C. H. T. P. Modelagem de proteínas-alvo por homologia estrutural. Revista Eletrônica de Farmácia, v. 4, n. 1, p. 15-26, 2007.

STEWART, J. J. P. Application of localized molecular orbitals to the solution of semiempirical selfconsistent field equations. International Journal of Quantum Chemistry, v. 58, n. 2, p. 133-146, 1996.

TAYLOR, R. D.; JEWSBURY, P. J.; ESSEX, Jonathan W. A review of protein-small molecule docking methods. Journal of Computer-Aided Molecular Design, v. 16, n. 3, p. 151-166, 2002.

TROTT, O.; OLSON, A. J.; AutoDock Vina: improving the speed and accuracy of docking with a new scoring function, efficient optimization, and multithreading. Journal of Computational Chemistry, v. 31, n. 2, p. 455-461, 2010.

ZERNER, M. C. Semiempirical molecular orbital methods. Reviews in Computational Chemistry, p. 313-365, 1991. 